Saudi Journal of Oral and Dental Research

Abbreviated Key Title: Saudi J Oral Dent Res

ISSN 2518-1300 (Print) |ISSN 2518-1297 (Online)

Scholars Middle East Publishers, Dubai, United Arab Emirates

Journal homepage: https://saudijournals.com

Case Report

\title{
Defective Dental Restorations: A Case Series
}

Ahmed O Shami*, Ahmed H. Khadhi, Khalid A. Arishi, Shaker M Hakami, Amal Mohammed Jabari

Dental Intern, College of Dentistry, Jazan

DOI: 1 10.36348/sjodr.2021.v06i01.014 | Received: 01.01.2021 | Accepted: 09.01.2021 | Published: 20.01 .2021

*Corresponding author: Ahmed O Shami

\section{Abstract}

Dental restoration is nowadays becoming key dental treatments, especially use of the composites and replacement of missing teeth using dental fixed partial denture. These can provide temporary relief to the patient, but it had long term side-effects. This article presents case reports of defective composite restoration interdentally, defective cantilever bridge, defective amalgam restoration.

Keywords: Defective dentistry, Dental malpractice, Composite restoration.

Copyright $\odot 2021$ The Author(s): This is an open-access article distributed under the terms of the Creative Commons Attribution 4.0 International License (CC BY-NC 4.0) which permits unrestricted use, distribution, and reproduction in any medium for non-commercial use provided the original author and source are credited.

\section{INTRODUCTION}

The placement of dental restoration and repairing or replacement of dental restorations is one of the most common treatments done by general dental practitioners [1]. These procedures can be necessitated by marginal breakdown, restoration failure and/or recurrent caries [2].

Nowadays general dental practitioner's trend is towards the increased placement of composite resin restorations in practice. With the increasing use of composite resin materials for the restoration of defects in posterior teeth, there is a need to further develop the awareness of the proper techniques that optimize the performance of posterior composites in clinical service $[3,4]$.

This article presents case reports of defective composite restoration interdentally, defective_cantilever bridge and defective amalgam restoration.

\section{CASE REPORT}

\section{Case 1}

A 34 year old male patient came with a chief complaint of pain in the mandibular posterior region of right and left side, since 1 to 2 months. On examination, it was found that composite restoration was placed between second and third molars (Fig 1 A and B). Also, the OPG had shown the radiopaque composite restoration between second and third molars (Fig 1C). Because of this defective composite restoration, there was food lodgement below this composite restoration causing the gingival swelling and pain. The restoration was removed on right side and left side and the patient was given gum paint to apply locally and also given medication to decrease the gingival swelling and infection. 


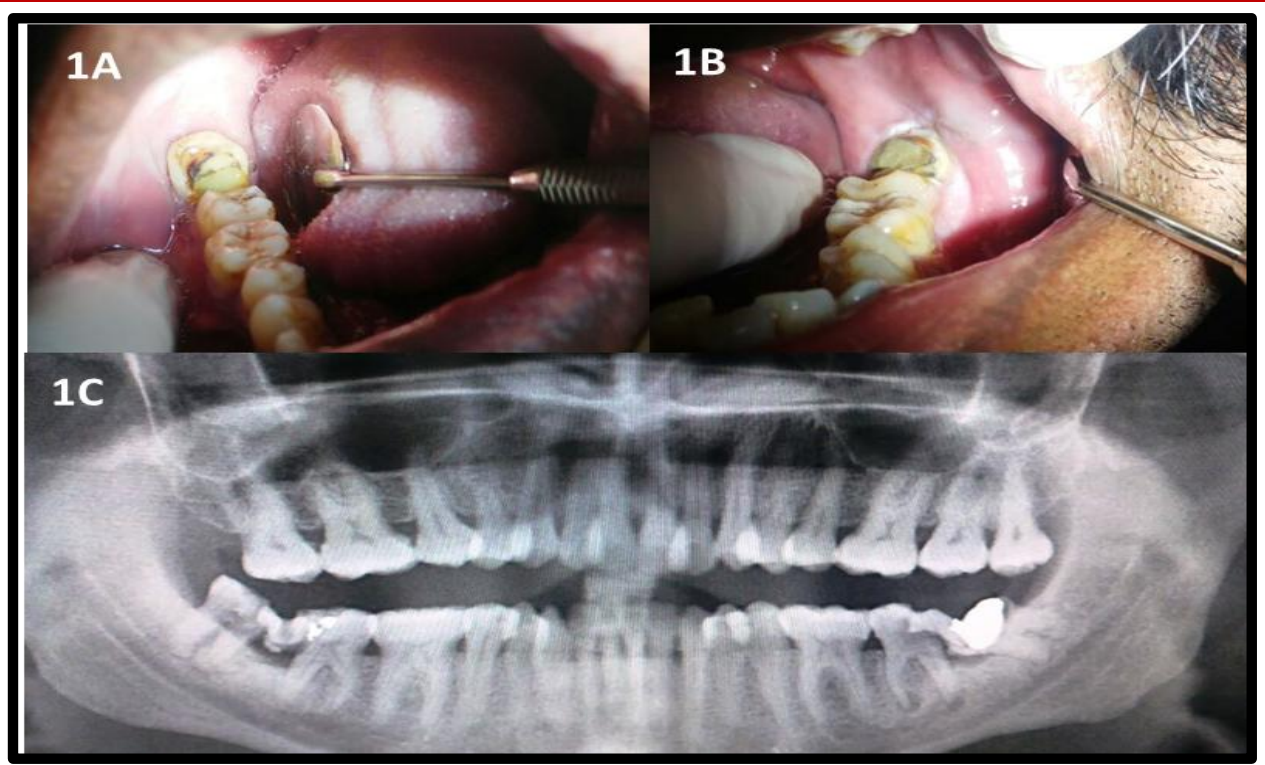

Fig-1: A) Intraoral photograph showing defective dental treatment on right side with composite restoration between mandibular second and third molars. B) Image showing defective dental treatment on left side with composite restoration between mandibular second and third molars. C) OPG showing radiopaque composite restoration between right and left mandibular second and third molars

\section{Case 2}

A 57 year old male patient came with a complaint of pain at the mandibular left posterior region since 15 days. On clinical examination, cantilever restorative bridge was present with pontic of mandibular second premolar and first molar and cantilever of second molar (Fig-2A). There was big gap was present between the base of cantilever tooth and the alveolar ridge allowing food lodgement. Radiographical examination had shown radiolucency present on the distal root of mandibular first molar and cantilever second molar (Fig-2B). Because of gap between the base of cantilever tooth and alveolar ridge, food lodgement was present and it caused caries on the distal surface of first molar and also resulted in the gingival lesion and bone loss. The cantilever part of the bridge was removed with the help of bur (Fig 2C and D) and the treatment for the bone gingivitis was done and the patient was kept on follow-up.

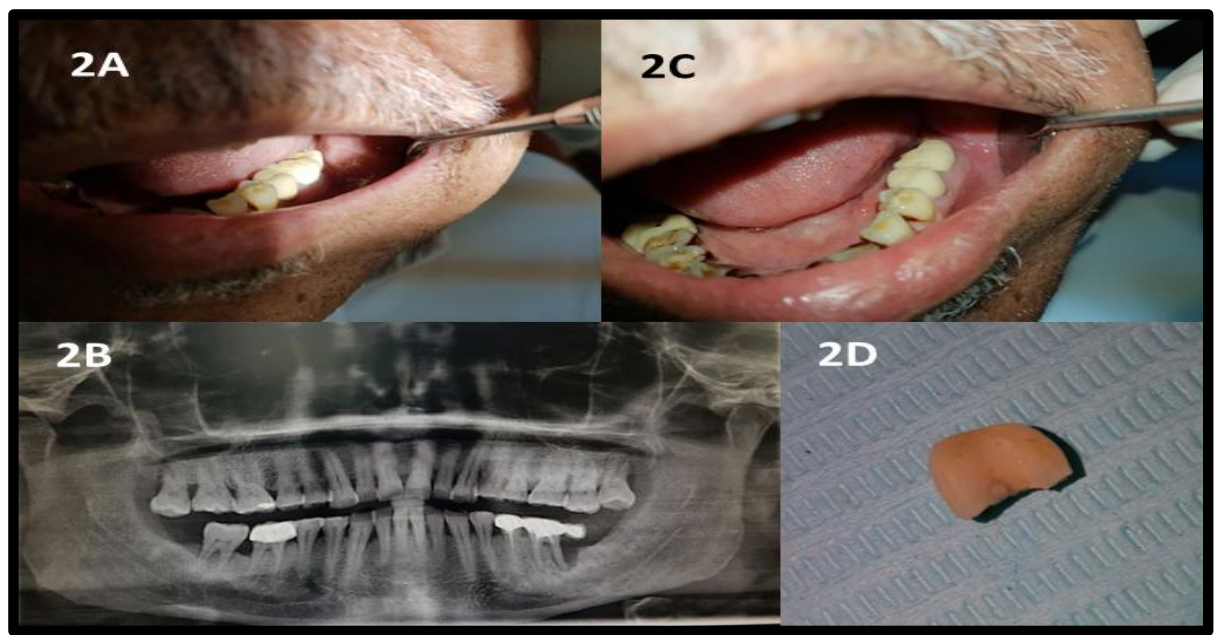

Fig-2: A) Intraoral photograph of the patient showing presence of cantilever bridge extending from Mandibular second premolar to second molar on left side. B) OPG showing the cantilever bridge. C) After removal of the cantilever tooth. D) The removed cantilever part of the bridge.

\section{Case-3}

A 47 year old male patient came with a complaint of pain in the interdental area between mandibular left second premolar and first molar teeth. On clinical examination it was found that amalgam restoration was placed extending from cavity of disto- occlusal of second premolar and mesio-occlusal of first molar (Fig-3). Below this restoration gap was present causing food lodgment and the gingival irritation. The defective restoration was removed and patient was given gum paint for the local application. 


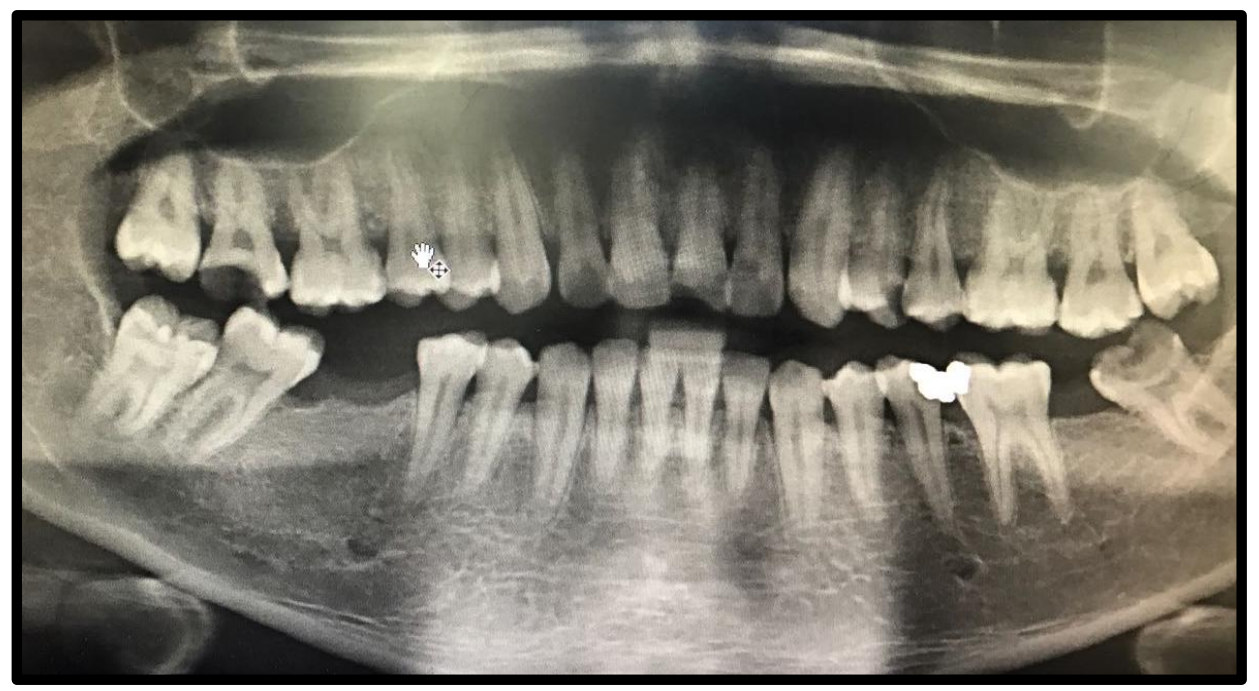

Fig-3: OPG showing defective amalgam restoration in the interdental area between left mandibular second premolar and first molar

\section{DISCUSSION}

Recently more developments is taking place in the dental materials and one of the most significant advances in dental practice in recent times has been the shift from a "mechanically focused" to a more "biologically focused", approach across the spectrum of dentistry, with an emphasis on minimally invasive treatments, like the use of composite restorations $[5,6]$.

It is essential that excess composite resin is not allowed to pool in interdental or cervical areas where it may lead to various complications [2].

In the present case report 1 , excess composite restoration and in case report 3 excess amalgam restoration was placed in the interdental areas and which was resulted in the complications.

Recent studies had shown that most of all posterior restorations were replaced and only few percentages of them were repaired. Factors associated with restoration repair were more recent dental graduates, restorations other than amalgam and older patients [2].

In the second case report, the cantilever bridge was not properly constructed and which resulted in the problems associated with the adjacent tooth. These type of fault or defect in the restoration can be avoided by the proper education of the dental practitioner and further loss of the dental structure or dental problems in the future can be avoided.

\section{CONCLUSION}

Awareness should be increased to avoid such type of restorations, so that it can be beneficial to the patients, by decreasing future complications. Increased clinical education should be given to the dental practitioners about the correct techniques and its implications.

\section{REFERENCES}

1. Sharif, M. O., Catleugh, M., Merry, A., Tickle, M., Dunne, S. M., Brunton, P., ... \& Chong, L. Y. (2014). Replacement versus repair of defective restorations in adults: resin composite. Cochrane database of systematic reviews, (2).

2. Fayyaz, A., Fareed, M. A., Ehsan, S., Baig, Q. A., \& Noor, N. A. (2015). Repair or replacement of defective direct composite restorations: a survey of dentists. Journal Pakistan Dental Association, 24(1), 17-21.

3. Blum, I. R., Jagger, D. C., \& Wilson, N. H. (2011). Defective dental restorations: to repair or not to repair? Part 1: direct composite restorations. Dental update, 38(2), 78-84.

4. Tovo, C. B., de Castilhos, E. D., \& Junior, S. A. R. (2011). Repair of composite restorations-Teaching information from dental schools of the State of Rio Grande do Sul (RS), Brazil. Revista da Faculdade de Odontologia-UPF, 16(3):301-306.

5. Lynch, C. D., Hayashi, M., Seow, L. L., Blum, I. R., \& Wilson, N. H. F. (2013). The management of defective resin composite restorations: current trends in dental school teaching in Japan. Operative Dentistry, 38(5), 497-504.

6. Gordan, V. V., Riley III, J., Geraldeli, S., Williams, O. D., Spoto III, J. C., Gilbert, G. H., \& National Dental PBRN Collaborative Group. (2014). The decision to repair or replace a defective restoration is affected by who placed the original restoration: findings from the National Dental PBRN. Journal of dentistry, 42(12), 15281534. 